\title{
'Relevancing' Communication and Study Skills Courses
}

\author{
Philip H. Mhundwa \\ phmhundwa@buse.ac.zw
}

\section{ABSTRACT}

Defined in contexts of general theories and practice of education, the terms relevant or relevance are used to indicate whether or not educational activities or processes involved in teaching-learning situations add value to or enhance students' psycho-social as well as intellectual skills in the analysis, application and communication of the knowledge or skills they acquire or develop during the learning process. It is generally understood that the acquisition of knowledge in specified disciplines is facilitated by students' communication proficiency levels in the use, not only of the medium of communication used, but by, also, their familiarity with the discourse studies used to communicate information in specified disciplines. The discourse strategies used in different subject disciplines are generally referred to as, English for Specific Purposes (ESP).

\section{Introduction}

The focus of discussion in this article is related to the need for ensuring that subject content taught in universities or other institutions of learning are linked to students' anticipated professional needs. In this article, the word 'relevancing' is used in the active form to refer to processes that institutions should put in place to ensure that courses offered are in keeping with or recognise the professional aspirations of students. This observation suggests that Communication Skills courses should, in addition to teaching students how to communicate through English, focus on the specific types of English they are likely to use in specific professional or social situations. It is with the intention to achieve this objective that in this article, the writer suggests we review the Communication Skills Courses we offer in order to package into them, study topics and teaching strategies that help students develop notions of the meaning and skills for applying relevant and or appropriate communication skills in scientific written or spoken discourse.

\section{Definition of the Concept 'Relevance'}

Communication is a broad psycho-sociological concept. Definition of the term 'relevance' is therefore, conceptually relative, in that situational or communicative notions definitions of the term can, depending on the texts in which it used in this discussion, the writer suggests we define 'relevance; with reference to the academic context in which Communication and Study Skills Courses are taught at 
Bindura University of Science Education. Understanding the implications of the phrase 'Science Education' implies that scientific theories and content are taught, perhaps differentially, in different faculties and departments but whatever differences we might find between and or among such sub-disciplines should be perceived as having scientific justification.

In this context, scientific teaching strategies could be distinguished from scientific learning content but ideally the two approaches to definitions of science as content or scientific as a teaching learning strategy would be issues lecturers make and apply in contexts determined by their conceptualisations of students' academic needs.

\section{'Relevancing' Communication and Study Skills}

In contexts of Communication and Study Skills, relevancing teaching/learning content can be defined as the establishment of links or connections between what is to be connected (i.e. content) and the mode or transmission code considered appropriate and effective for communicating the desired information or content (i.e. linguistic mode or its characteristics in terms of lexical items as well as syntactic structures used and the information or semantic implications of the language used). The positive relationship between the mode of communicating scientific concepts and the concepts communicated leads to our understanding of the term English for Specific Purposes, a term which Richards et.al (1997: 125) define as:

"The role of English in a language course or programme of instruction in which the content and aims of the course are fixed by the specific needs of a particular group of learners. For example courses in English for Academic Purposes, English for Science and Technology and English for Nursing."

In this context "Relevancing Communication and Study Skills" involves focussing the study towards ways in which language is used to express ideas or exchange information using language forms such as lexical items as well as syntactic structures that effectively and appropriately communicate the intended content. Studies in English for Specific Purposes reveal that certain words, phrases or sentences can be used differentially or identically in certain situations.

Defining English for Specific Purposes in this manner further suggests that the varieties or types of language or communication used in different social or academic situations (such as science, agriculture, engineering or nursing) require that writers or communicators select linguistic units, that is words or sentences that appropriately communicate desired information. In their Dictionary of Language and Linguistics Hartmann and Stork (1976: 95) define the term relativity as the communicator's ability to select linguistic features that accurately reflect a speaker or writer's view of the world or notions that they communicate to their audiences. It is the communicator's ability to carefully select and appropriately use linguistic units that adequately and successfully communicate ideas to the audiences 
addressed. We can, therefore, simply refer to the term linguistic reference as implying that language users should ensure that the language used when communicating information is relevant or appropriate lexically, syntactical and semantically, hence, the use in this text of the term relevance. In the context of discussion in this article, readers are therefore advised to define the term relevance as suggesting that the communication of concepts in spoken or written discourse has features that clearly and accurately take cognizance of the fact that in communication lexical and syntactic structures are used to appropriately communicate ideas or information in given discussion or reported topics. What this implies is that subjects such as science, art, philosophy call for use of certain lexical, syntactic and semantic desired information. In other words certain sets of meaning or certain usage this way or ensuring that the language used in different contexts subject disciplines should be relevant.

In this context, therefore, the term relevancing is used to refer to the writer's ability to use language ensuring that the style of language used appropriately communicates ideas in the general field or register of discourse in this context, the term 'register' can be defined as:

"Linguistic varieties that are linked ... to occupations, professions or topics... Registers are simply a rather special case of a particular kind of language being produced by the social situation." $\quad$ (Trudgill 1983:101)

The discourse style used is, in some cases, influenced by the status of the speech participants as in the case of daughter-in-law speaking to a father-in-law.

e.g. How are you doing? (father to daughter).

How are you doing? (husband to wife).

How are you doing? (boyfriend to girlfriend).

In such cases, utterance meanings can be defined as being contextually differentiated.

\section{Course Outline Suggestions}

Course outlines for teaching students in different institutions generally vary depending on:

\section{1) Learner's Background}

Academic or experiential background analysis requires that prior to establishing learning or teaching course outlines, instructors should study or investigate the background information students would have acquired prior to coming to school or university. It is necessary that we establish students' background information in order to appropriately link previous learners' knowledge or experiences to that which they would be taught at school or university. Apart from such findings enabling teachers link previous and new knowledge. 
Background knowledge enables syllabus designers and lecturers determine:-

a) Learner's assumed previous knowledge.

b) Ways of linking previously acquired and new knowledge.

c) Determine, on the basis of findings/observations of a) and b), how to teach students to acquire new knowledge and ways in which ne knowledge can be linked to previous knowledge.

d) On the basis of previously acquired linguistic knowledge or communication through previously learned languages proceed to determine:-

- The language students need to use in studying specific topics.

- The language that appropriately communicates ideas in given disciplines or subjects i.e. ESP.

\section{2) Course Components}

N.B. No fixed approach

Section A: General English (EGP)

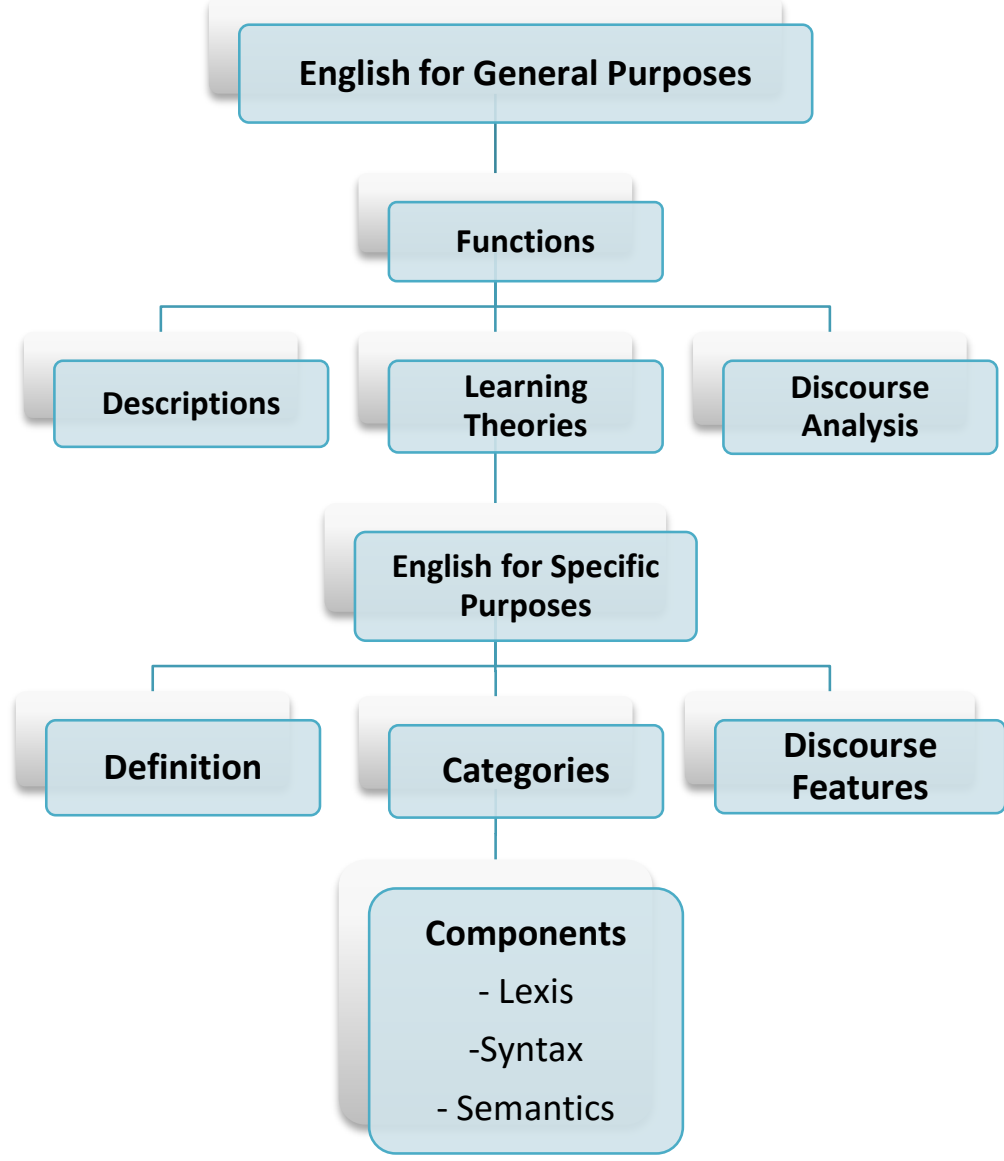




\section{'Relevancing' Communication and Study Skills Courses}

The preceding brief description of the concept "English for Specific Purposes" (ESP), suggests that, it is high time Communication and Study Skills Courses get revised to ensure that the core content of the courses offered is based on developing students proficiency in communicating scientific information in ways that we generally assumes to be acceptable to members of the scientific discourse community. The review suggested here should focus on the linguistic needs and proficiency levels expected from graduates in a university of science education or science and technology (i.e. Bindura University of Science Education). Such linguistic focus on needs and discourse typology in which language is used ensures that course outlines in Communication Skills courses are generally based on the theory of relevance. A theory that can be defined as - The acquisition and application of such linguistic discourse ensures that our Communication Skills Courses respond to, over and above proficiency in Communication Skills, competency and fluency in the communication of subject based or professing subject based skills using appropriate or professionally acceptable discourse.

As we consider this proposal, we should be aware that the definition of science as an academic discipline may mean and suggest analysing pedagogical theories and practices that require defining communication from different angles. We might therefore, in our efforts to define scientific spoken and written discourse identify what we might ourselves be referring to as "Varieties of Scientific Discourse" applied in the teaching of different scientific disciplines in different faculties.

\section{Implications}

The information presented in this brief article is a tentative suggestion that Communication and Study Skills Courses for a Zimbabwean University should be more ESP oriented or learn more closely towards the study of scientific discourse with reference to the following sub-fields of study.

- Scientific lexis

- Scientific syntax (including all possible variations)

- Scientific semantics e.g. SVO, OVS, SV, OV.

- General characteristics and stylistic variations of scientific and or other discourse types used in different faculties and departments.

Instead of adopting a communication and study skills approach that focuses entirely upon ESP communication, we can provide courses that introduce students to different communication and study skills courses. Such courses would aim to introduce first year students to communication and study skills content that is presented, differently, in sections such as the following:

Section A: Study Skills

1. Reading for Academic Purposes.

2. Analysing Question Elements. 
3. Listening Skills (receptive skills).

4. Speaking Skills.

5. Writing Skills.

6. Essay writing/presentation.

\section{Section B:}

1. Written Communication

2. Oral Communication

3. Varieties of Discourse Oral and Written Discourse types

\section{Section C:}

1. ESP - meaning and Definition

2. ESP - varieties e.g.

i. Scientific discourse.

ii. Social Discourse.

iii. Medical Discourse.

- Topic sentence.

- Topic sentence developers.

- Paragraph conclusions.

iv. Academic Communication vs. Social Communication.

v. Introduction to Discourse Analysis (i.e. meaning and practices.

Section C constitutes an important unit or section of communication skills in a university of science education. Whichever way we define science in science in science education, it is, imperative that we orientate our communication and study skills towards teaching English for Specific Purposes. In this case we claim to focus on studying science based courses irrespective of the definitions we give to the discipline 'science' we used to provide communication skills courses that focus on what we, in this context, refer to as science. Such an approach would compel us to focus on designing ESP Communication Skills courses.

Admittedly, there would be need to add other functionally related topics to ESP courses in order to ensure that the Communication Skills courses, under instruction, respond to the communication needs of learners. Richards et al. (2014) defines this LSP as follows:

Second or foreign language used for particular and restructured type of communication (e.g. for medical reports, scientific writing, air traffic control). Other linguistic features which are different from ordinary language. In language teaching decisions must be made as to whether a learner or groups of learners requires a language for general purposes or for special purposes. 
It is, however, advisable that in ESP Communication Skills courses, that content should be sectionalised as follows:

- $\quad$ meaning of communication skills

- $\quad$ varieties of communication skills

i. social communication skills

ii. interactive communication skills

iii. academic communication skills

iv. discipline based communication skills or professionally based communication skills (i.e. ESP)

ESP discourse can vary from situation to situation depending on the discourse topic chosen by speakers. Generally ESP is a term used to refer to a variety or type of language used in situations where ideas or meanings are linked to or relate to certain categories of meaning. Hutchinson and Waters (1987:19) provide the following definition

ESP must be seen as an approach not a product. ESP is not a particular kind of language or methodology nor does it consist of a particular type of teaching material. Understood properly, it is an approach to language teaching, which is based on learner need.

The foundation of all ESP is the simple question: why does this learner need to learn a foreign language? From this question, will flow a whole lot of further questions, some of which will relate to the learners themselves, some to the nature of the language the learners will need to operate some to the given learning context. ESP, then, is an approach to language teaching in which all decisions as to content and method are based on learner's reason for learning.

Readers might wonder why the writer got motivated to provide this lengthy citation in a simple article focussing on the relevance of communication skills in a subject that is generally considered minor among other university courses. The reason for the writer's motive to do so can be briefly stated as follows: the role of language in teaching and learning situations, in its various ESP forms, is an important constituent if not facilitator of all effective learning activities. It is this view of the role of language in communication that has led to the elevation of communication skills to the high academic status we find it.

This offers learners the opportunity to understand that Communication and Study Skills courses can vary from institution to institution, depending on whether the academic courses offered are scientific or non-scientific. What academic approach selected by schools, the need to combine General Communication Skills content or English for Specific Courses such as science, theology, agriculture etc. maybe found desirable. It is this suggestion that led Richards et al. to advise that:

In language teaching, decisions must be made as to whether a learner or group of learners require a language for general purposes or for special purposes. Richards et.al. (op cit. 204). 


\section{References}

Hartmann, R. R. K. and Stork, F. C. Dictionary of Language and Linguistics. The Language Centre University of Nottingham and Sheffield: United Kingdom.

Hutchinson, T. and Waters, A. 1987. English for Specific Purposes: New Directions in Language Teaching. Cambridge University Press: Cambridge.

Mhundwa, P. H. 2007. Readings in the Theory and Teaching of Communication and Study Skills. Mambo Press: Gweru.

Richards, J. C., Platt, H. and Platt, H. 1992. Dictionary of Language Teaching and Applied Linguistics. Longman: London.

Widdowson, H. G. 1978. Teaching Language as Communication. Oxford University Press, Oxford. 